\title{
Research on Temporal and Spatial Dynamic of Maize Drought Using Remote Sensing: A Case on Shuanghe Farm of Beijing
}

\author{
Yunxiang Jin ${ }^{1,2}$, Sijian Zhao ${ }^{1,2}$, Wei Sun ${ }^{1,2}$, Lei Xu ${ }^{1,2}$, Qian Nie ${ }^{1,2}$, Qiao Zhang ${ }^{1,2^{*}}$ \\ ${ }^{1}$ Agricultural Information Institute, Chinese Academy of Agricultural Sciences, Beijing 100081, China \\ ${ }^{2}$ Key Laboratory of Agri-information Service Technology, Ministry of Agriculture, Beijing 100081, \\ China
}

\author{
基于遥感数据的玉米旱情时空变化研究 \\ 一以北京双河农场为例 \\ 金云翔 ${ }^{1,2}$, 赵思健 ${ }^{1,2}$, 孙伟 ${ }^{1,2}$, 徐否 ${ }^{1,2}$, 聂谦 ${ }^{1,2}$, 张峭 $1,2^{*}$ \\ 1 中国农业科学院农业信息研究所, 北京 100081 , 中国 \\ 2 农业部农业信息服务技术重点实验室，北京 100081 , 中国
}

\begin{abstract}
Drought, which is one of main meteorological disasters, always affects maize production. Remote sensing has become an important and effective technology for maize drought monitoring and assessment. In this paper, maize planting region in Shuanghe farm of Beijing was selected as study areas. We calculated SPI (standardized precipitation index) using meteorological data during 1985 to 2014 and confirmed years of drought events. Then, based on 16 day composite MODIS NDVI products between 2000 and 2014, the model to monitor maize drought was established by anomaly vegetation index (AVI). The drought grades were classified into three levels including serious drought, medium drought and slight drought. The temporal and spatial changes of drought were monitoring in the growth period of maize. This study could offer scientific decision to agricultural production and disaster reduction to avoid disaster. It also could offer a novel technique method to risk
\end{abstract}

“通讯作者: 张峭 (1961-), 山西人, 博士, 研究员, 研究方向：农业保险与农村金融, E-mail: zhangqiao@caas.cn. assessment of disaster.

Keywords: maize, drought, anomaly vegetation index

\section{摘要}

干旱是造成玉米减产的主要气象灾害, 利用遥感技术 进行玉米旱情监测与评估已成为一种重要而有效的 技术手段。本研究以北京双河农场玉米种植区为研究 对象, 依据 1985-2014 年的气象资料采用 SPI 指数(标 准化降水指数) 确定干旱事件发生年。在此基础上, 基于 2000-2014 年 MODIS NDVI 16 天合成产品数据, 利用距平植被指数 (AVI) 建立玉米旱情监测模型, 对玉米主产区的干旱程度划分为重旱、中旱和轻旱三 个等级, 对玉米生育期旱情的时空变化进行连续监测。 监测结果可以为农业生产、减灾避灾提供科学的决策 依据, 也为灾害风险评估提供新的技术方法和手段。

关键词: 玉米; 旱情; 距平植被指数

1. 引言

由于长期降水短缺造成的干旱是一个全球性的 问题, 旱灾已成为我国影响范围最广、发生最频繁的 气象灾害 ${ }^{[1]}$, 其发生的随机性强、持续时间长、波及 范围大对农业生产的影响尤为显著 ${ }^{[2-3]}$ 。据统计中国 
Risk Analysis and Crisis Response in Big Data Era (RAC-16)

平均每年受早面积约 2100 多万 $\mathrm{hm}^{2}$, 约占耕地面积 的 $20 \%{ }^{[4]}$, 在当前全球气候变暖的大背景下, 干旱对 地区社会经济发展的制约作用更为突显。

近些年来, 干旱监测技术手段不断提高, 由相对 单一的地面站点观测数据, 如气象站点和水文站点等, 向多元化、新型观测手段的发展, 如遥感卫星、地面 传感器等, 使得观测范围、时效及精度显著提高。随 着观测技术的发展, 干旱监测方法也在逐步提高和完 善, 早期使用单一气象要素或多种气象要素的简单组 合进行干旱监测, 方法较为简单, 考虑因素较少 ${ }^{[5]}$ 。 而遥感数据具有观测范围大、受地理条件限制小等优 势, 遥感数据的不同光谱波段组合和建立的干旱监测 模型可以应用到农作物旱情监测中。

基于遥感和 GIS 技术的风险分析和评估已得到 实际应用, 例如 Ding 和 Miao ${ }^{[6]}$ 基于 GIS 技术对芦山 地震灾区滑坡风险进行了分析评估, 制作了滑坡灾害 风险等级图, 可以为灾后恢复和重建、人员合理安置 提供决策支持。Zhuo 等 ${ }^{[7]}$ 利用遥感数据估算了锡林 郭勒盟各月份的草原可燃物存量, 建立了多因子火险 指数, 有效表达了地表可燃物致灾的风险程度。现阶 段, 使用遥感数据进行干早监测主要集中于植被指数、 地表温度和微波获取的土壤水分数据反映干旱程度 ${ }^{[8-11]}$, 而对于农业旱情的时空变化以及风险识别和分 析研究相对较少。

北京双河农场是重要的优质玉米生产基地, 由于 降水的季节分布不均和年际变化幅度较大, 地区季节 性干旱频发。因此, 本研究以北京双河农场玉米种植 区为研究对象, 建立基于遥感数据的玉米旱情监测模 型, 开展玉米早情的时空变化研究, 识别区域旱情程 度, 为指导防灾和备灾、减少旱灾损失提供决策依据。 同时, 玉米产区的旱情变化研究对于合理制定农业种 植制度、区域安全和粮食保障具有重要的指导意义。

\section{2. 研究区概况}

北京双河农场位于黑龙江省西部齐齐哈尔市甘 南县境内 (图 1), 处于濑江右岸、大兴安岭南坡与 松嫩平原交界处 (东经 $120^{\circ} 38^{\prime}-120^{\circ} 57^{\prime} \mathrm{E}$; 北纬 $47^{\circ} 41^{\prime}$ - $48^{\circ} 01^{\prime} \mathrm{N}$ ), 是北京“飞”的最远的一块飞地。土地面 积 $380 \mathrm{~km}^{2}$, 年均温约为 $3.2^{\circ} \mathrm{C}$, 年降水量约为 $416.5 \mathrm{~mm}$, 属于大陆性亚寒带气候, 处于黑龙江省第 二积温带和第三积温带之间。土质肥沃, 土壤有机质 含量在 3-6.52 之间, 日照充足, 水资源丰富, 适宜玉 米、水稻、大豆、小麦等作物种植。下设 21 个生产 队, 拥有耕地 40 多万亩, 其中农场北部为旱田, 以 玉米种植为主。本研究选取双河农场北部玉米种植区 的核心区为研究区 (图 2)。

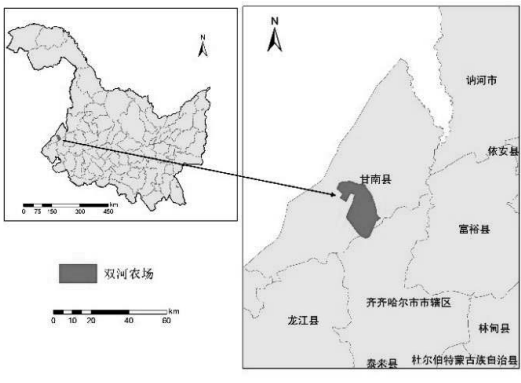

图 1 双河农场区位图

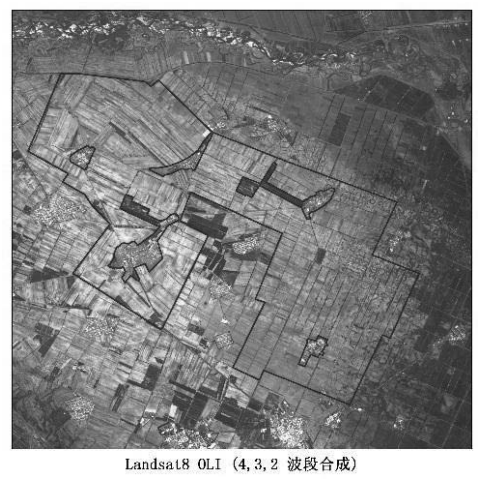

图 2 玉米核心区

\section{3. 数据与方法}

\section{1 气象数据与方法}

本研究气象数据来源于双河农场气象站提供的 1985-2014年双河农场地区的月度气象数据。采用 SPI 指数 (标准化降水指数) 确定干旱事件发生年。SPI 是基于累积降水概率的干旱指数, 该指数对降水的分 布可以使用 Gamma 分布较好的进行拟合, 然后使用 累积概率函数对降水分布进行描述。对于某一特定时 期的降水, 通过与该累积函数来进行比较即可获知该 时期的降水偏离正常降水的程度。SPI 的计算公式及 步骤参见《气象干早等级》(GB/T20481-2006) ${ }^{[12]}$ (表 1)。

\begin{tabular}{cc} 
表 1 & SPI 划分干旱事件等级 \\
\hline 干早事件 & SPI 值 \\
\hline 正常 & SPI $>-0.5$ \\
轻旱 & $-1.0<\mathrm{SPI} \leq-0.5$ \\
中旱 & $-1.5<\mathrm{SPI} \leq-1.0$ \\
重旱 & $-2.0<\mathrm{SPI} \leq-1.5$ \\
特早 & $\mathrm{SPI} \leq-2.0$ \\
\hline
\end{tabular}


Risk Analysis and Crisis Response in Big Data Era (RAC-16)

\section{2 遥感数据与预处理}

遥感数据采用美国国家航空航天局（NASA）官 方网站下载的 MODIS NDVI 16 天合成产品数据 (MOD13Q1), 时间分辨率为 16 天, 空间分辨率为 $250 \mathrm{~m}$ 。本研究选用 2000-2014 年玉米播种生长到成 熟收获期（5月上旬-10月上旬）的每年共 10 期遥感 数据。利用 MRT 软件对遥感数据进行投影转换、格 式转换和重采样, 计算得到 2000-2014 年玉米生育期 的 NDVI。

为了确定双河农场玉米种植核心区, 本研究选取 了 Landsat 系列 Landsat8 OLI 卫星数据, 时间为 2015 年 6 月 14 日, 多光谱数据为 $30 \mathrm{~m}$, 全色波段数据为 $15 \mathrm{~m}$ 。经过辐射定标、大气校正和数据融合处理, 形 成双河农场 $15 \mathrm{~m}$ 的多光谱遥感数据。采用人机交互 解译方法, 结合图像增强、图像拉伸等处理, 得到双 河农场玉米种植核心区 (图 2)。

\section{3 玉米旱情模型构建及等级划分}

植被指数是遥感监测地面植被生长状况的指标, 可以较好反映地表植被的生长和分布状况 ${ }^{[13]}$ 。当作物 缺水时, 作物的生长受到抑制, 叶片内的叶绿素含量 下降, 近红外光反射率降低, 植被指数值下降, 以此 来表征干旱程度 ${ }^{[14]}$ 。本研究将某一时期玉米的 $N D V I$ 与多年同期玉米 $N D V I$ 的平均值进行比较, 建立玉米 旱情监测模型:

$$
A V I_{i, j}=\frac{N D V I_{i, j}-\overline{N D V I_{j}}}{\overline{N D V I_{j}}}
$$

其中, $A V I_{i, j}$ 为第 $i$ 年的第 $j$ 时期的距平植被指 数, $N D V I_{i, j}$ 为第 $i$ 年的第 $j$ 时期的 $N D V I, \overline{N D V I_{j}}$ 为 第 $j$ 时期的多年 $N D V I$ 平均值。某一时期的 $N D V I$ 值 与同时期多年平均值的相对离差, 反映了偏旱或偏涝 的程度, 由此可以确定区域的旱情等级。陈维英等 ${ }^{[15]}$ 研究得出 $A V I$ 分级, $-0.2<A V I<-0.1$ 表示干旱的出 现, $-0.6<A V I<-0.3$ 表示重早, 因此将 $A V I \geq-0.1$ 判 定为未出现早情。参考陈维英等和江东等 ${ }^{[15-16]}$ 研究结 果, 结合研究区的区域特征, 我们将玉米旱情划分为 重旱、中旱和轻旱三个等级, $A V I<-0.3$ 表示重早; $-0.3 \leq A V I<-0.2$ 表示中早; $-0.2 \leq A V I<-0.1$ 表示轻旱。

\section{4. 结果分析}

\section{1 典型干旱年的确定}

通过计算年 SPI 指数得到, 2000-2014 年间双河 农场地区处于干旱的年份较多 (图 3), 其中重旱年 份为 2004 年; 中早年份有 3 个, 分别为 2001 年、2007
年和 2010 年; 轻早年份有 3 个分别为 2000 年、 2006 年和 2008 年。而处于正常年份的有 5 个, 分别为 2002 年、 2005 年、 2011 年、 2012 年和 2014 年。SPI 描述 的是气象干旱发生的阶段, 气象干旱可以一定程度上 反映农业干旱的发生, 根据 SPI 气象干旱等级划分, 结合双河农场的实际情况, 选取中旱以上等级的 2001 年、 2004 年、 2007 年以及 2010 年为典型干旱 年。

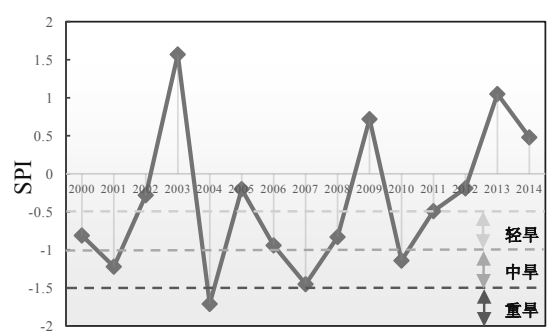

图 3 2000-2014 年双河农场 SPI

\section{2 玉米早情时间变化分析}

在玉米旱情监测模型中, 多年平均 $\overline{N D V I_{j}}$ 选择 2000-2014 年降水正常年份 (5 年) 的 $N D V I$ 平均值 （2002 年、2005 年、2011 年、 2012 年和 2014 年), 并根据玉米早情监测模型计算典型干旱年玉米生育 期不同阶段的 $A V I$, 通过阈值设定, 将玉米主产区早 情划分为轻旱、中旱和重旱。

根据 $A V I$ 计算得到双河农场典型干旱年不同时 期的玉米旱情 (图 4)。2001 年玉米生育期旱情波动 性较大, 对玉米生长发育影响较大, 其中 6 月中旬、 7 月中旬受旱面积最大, 占研究区的 $90 \%$ 以上, 尤其 在 6 月中旬中旱和重早面积占总面积的 $82 \%$ 。2004 年玉米生育期发生旱情主要集中于 6 月上旬到 7 月上 旬, 其中 6 月中旬受早面积占研究区总面积的 $87.4 \%$, 6 月下旬到 7 月上旬受早面积占总面积的 $64.7 \%$ 。该 段时间为玉米拔节期, 是玉米生长发育的关键期之一, 该时期发生旱情对玉米最终产量影响较大。2007 年 研究区早情主要发生在玉米生长期早期 5 月中旬和 玉米生长期后期 9 月中旬, 其中 5 月中旬受早面积占 总面积的 $61.6 \%, 9$ 月中旬大部分区域受到干旱的影 响, 受旱面积达到 $90 \%$ 以上。2007 年其他时间段旱 情不明显, 仅 6 月中旬和 7 月下旬有一定程度的轻早。 2010 年研究区早情主要发生在玉米生长发育的后期 9 月中下旬, 受早面积占总面积的 $90 \%$ 以上, 其中 9 月中旬几乎整个研究区均遭受到不同程度旱情影响。 
Risk Analysis and Crisis Response in Big Data Era (RAC-16)
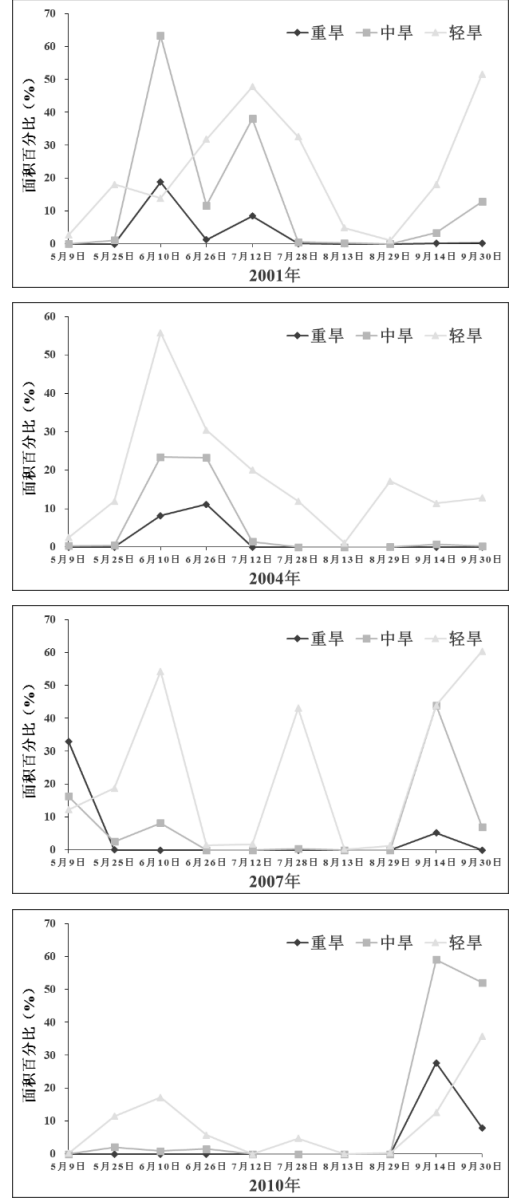

图 4 不同时期玉米旱情监测面积百分比

\section{3 玉米旱情空间变化分析}

根据研究区典型干旱年的时间变化分析, 在典型 干旱年中分别选取各年旱情较严重的一期进行玉米 旱情的空间分析, 四期分别为 2001 年 6 月 10 日、2004 年 6 月 10 日、 2007 年 9 月 14 日和 2010 年 9 月 14 日（图 5)。2001 年 6 月中旬整体处于偏中旱, 受旱 情影响较小的区域主要集中于东南部, 重旱区域主要 位于西北部, 轻旱、中旱、重旱面积分别占总面积的 $13.94 \% 、 63.23 \%$ 和 $18.82 \%$ 。2 004 年 6 月中旬整体处
于偏轻旱, 轻旱面积占总面积的一半以上, 受旱情影 响较小的区域也主要集中于东南部区域,而重旱主要 分布于中部和西北部局部地区, 轻旱、中旱、重旱面 积分别占总面积的 $55.75 \%$ 、23.46\%和 $8.19 \%$ 。对比 2001 年和 2004 年早情空间格局, 同一时期遭受旱情 较严重的区域基本相同, 西北部区域在 6 月中旬应特 别关注旱情对玉米产量的影响。2007 年 9 月中旬整 体处于中旱偏轻旱, 受旱情影响较大的区域分布于东 南部和西北部局部区域, 未受旱情影响的区域主要位 于西北部和中部局部区域, 轻旱、中旱、重旱面积分 别占总面积的 $43.94 \% 、 43.94 \%$ 和 $5.20 \%$ 。2 010 年 9 月中旬整体处于中旱偏重旱, 受旱情影响较大的区域 分布于东南部和西北部, 轻旱的区域位于西南部, 未 受旱情影响的零散分布于中部地区, 轻旱、中旱、重 旱面积分别占总面积的 $12.60 \%$ 、59.06\%和 $27.64 \%$ 。 对比 2007 年和 2010 年早情空间格局, 同一时间重早 区域分布基本相同, 分布于研究区西北部和东南部。

\section{5. 结论与讨论}

本文首先采用 SPI 指数计算得到典型干旱年, 利 用 MODIS NDVI 遥感数据产品, 对黑龙江北京双河 农场玉米生育期内旱情进行监测, 分析了玉米生育期 内的旱情时空分布变化。研究结果表明, 研究区 2001 年玉米生育期旱情波动性较大, 其中 6 月中旬、 7 月 中旬受早面积最大，重旱区域集中于西北部； 2004 年玉米生育期旱情主要集中于 6 月上旬到 7 月上旬, 重旱主要分布于中部和西北部局部地区; 2007 年旱 情发生在玉米生长期早期和后期, 受旱情影响较大的 区域分布于东南部和西北部局部区域; 2010 年旱情 主要发生在玉米生长期的后期, 9 月中旬几乎整个研 究区均遭受不同程度的旱情, 受旱情影响较大的区域 分布于东南部和西北部。

在典型干旱年内, 通过 SPI 计算的干旱事件发生 月度与遥感监测的干旱发生期基本一致, 说明采用遥 感技术方法可以有效地监测玉米旱情发生时期和分 布区域。相比于气象站点得到的单一气象干旱指标, 在表征区域植被状况和分布方面, 遥感早情监测是农 学参数和气象因子的综合反映, 更符合作物生长实际 情况。遥感数据的高空间、高时间和高光谱分辨率提 供了可反映连续、大范围的地表信息, 为开展大范围 实时动态干旱监测提供了有效的数据源。遥感监测具 有监测范围广、速度快、成本低等特点, 具有广泛的 应用前景, 为旱情的实时监测预警、农业旱灾风险分 析与评估提供了重要的技术手段。 
Risk Analysis and Crisis Response in Big Data Era (RAC-16)
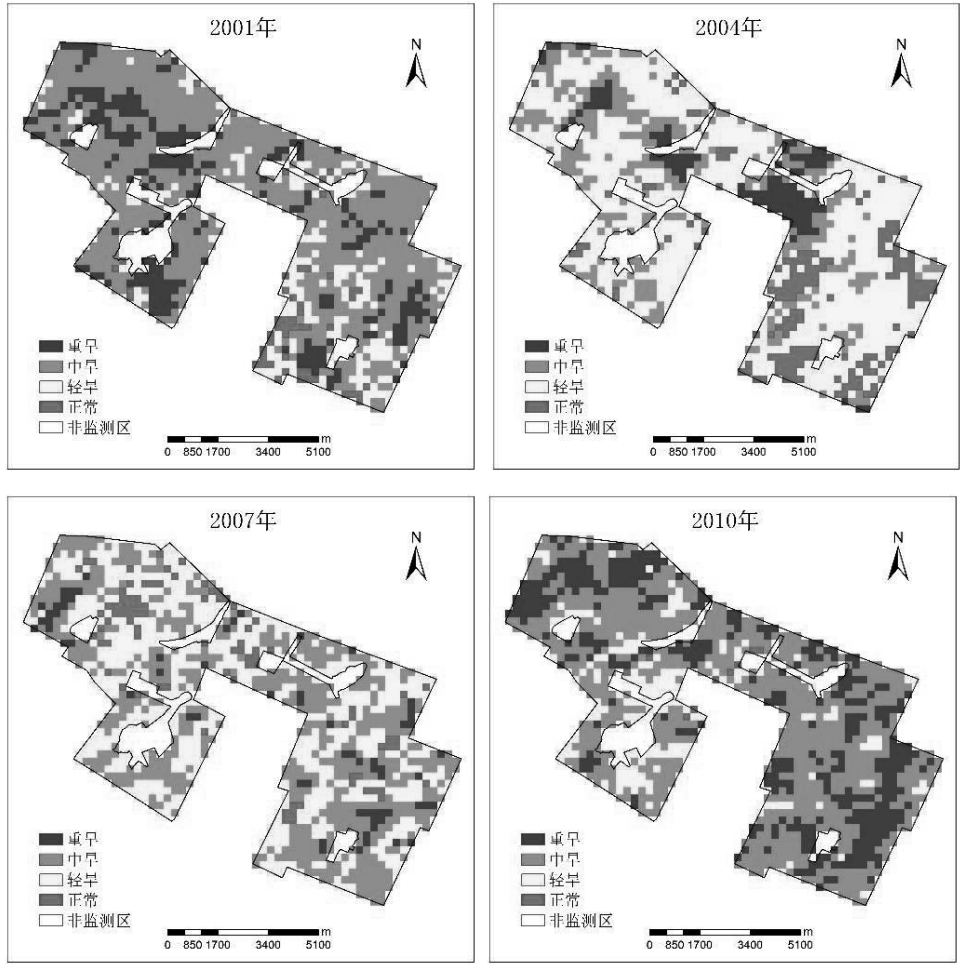

图 5 不同时期玉米旱情空间分布

虽然基于遥感数据的玉米旱情监测具有显著的

(Z141100002314007) 和科技部十二五科技支撑子课 优势特点, 但不能忽视种植结构调整、播种期变化、 题（2014BAL07B03-02）的资助。

播种面积比例变化等, 遥感数据也存在“同谱异物” 等混合像元问题的影响。同时, 本研究只针对玉米旱 情的时空变化进行了分析, 而早情发生后对玉米最终 产量的影响程度及定量分析, 仍将是今后研究的一个 重要方面。

\section{Acknowledgements}

This study was supported by Beijing Municipal Science and Technology Project (Z141100002314007), and National Science \& Technology Pillar Program during the Twelfth Five-year Plan Period (2014BAL07B03-02).

\section{致谢}

本研究得到了 2014 年北京市科技计划课题

\section{6. 参考文献}

[1] He Ying. Assessment Research of Bijie Drought Risk Based On Cloud Model. Journal of Risk Analysis and Crisis Response, 3(4), pp.192-200, 2013.

[2] 李茂松, 李森. 中国近 50 年旱灾灾情分析. 中国 农业气象, 24(1): 7-10, 2003.

[3] 覃志豪, 徐斌, 李茂松, 等. 我国主要农业气象 灾害机理与监测研究进展. 自然灾害学报, 14(2): 61-69, 2005.

[4] 王劲松, 郭江勇, 周跃武, 等. 干旱指标研究的 进展与展望. 干旱区地理, 30(1): 60-65, 2007.

[5] Richard R, Heim J R. A review of twentieth-century drought indices used in the United States. Bulletin of the American Meteorological Society, 83(8), pp.1149-1165, 
Risk Analysis and Crisis Response in Big Data Era (RAC-16)

2002.

[6] Ding Mingtao, Miao Cheng. GIS-based Assessment of Vulnerability to Landslide Hazards in Lushan Earthquake-stricken Areas. Journal of Risk Analysis and Crisis Response, 5(2), pp.93-106, 2015.

[7] Zhuo Yi, Liu Guixiang, Yu Fengming. The Combustible Materials Remote Sensing Ration Calculation and Fire Risk Dynamic Monitor in the Seasons of Withered Grass in Xilingoule Grassland. Journal of Risk Analysis and Crisis Response, 1(1), pp.65-74, 2011.

[8] 冯强, 田国良, 王昂生, 等. 基于植被状态指数的 全国干旱遥感监测试验研巧 (II) 一一干旱遥感监测 模型与结果分析部分. 干早区地理, 27(4): 477-484, 2005.

[9] 王鹏新, 吴高峰, 白雪娇, 刘俊明. 基于 Landsat 数据的条件植被温度指数空间升尺度转换方法. 农 业机械学报, 46(7): 264-271, 2015.

[10] Mu Q, Zhao M, Kimbal J S, et al. A remotely sensed global terrestrial drought severity index. Bulletin of the American Meteorological Society, 94(1), pp.83-98, 2013.

[11] Zhang A, Jia G. Monitoring meteofological drought in semiarid regions using multi-sensor microwave remote sesning data. Remote Sensing of Environment, 134, pp.12-23, 2013.

[12] 中国气象局. GB/T20481-2006 气象干旱等级. 中国标准出版社, 北京, 2006 年.

[13] 问娜, 杜继稳, 李登科, 等. 干旱遥感监测方法 研究应用进展. 灾害学, 23(4): 117-121, 2008.

[14] 胡荣辰, 朱宝, 孙佳丽. 干旱遥感监测中不同指 数方法的比较研究. 安徽农业科学, 37(17): 8289-8291, 2009

[15] 陈维英, 肖乾广, 盛永伟. 距平植被指数在 1992 年特大干旱监测中的应用。环境遥感，9：106-112, 1994.

[16] 江东, 付晶莹, 庄大方, 等. 2008-2009 年中国北 方干旱遥感动态监测. 自然灾害学报, 21(3): 92-101, 2012. 